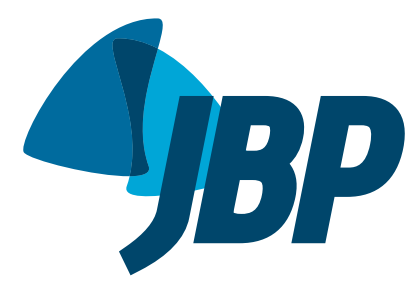

1. Faculdade Nova Roma, Recife (PE) Brasil.

2. Universidade de Pernambuco - UPE Recife (PE) Brasil.

3. Universidade Federal de Pernambuco UFPE - Recife (PE) Brasil.

a. (ID) $h t t p: / / o r c i d . o r g / 0000-0002-4618-2730$

b. iD http://orcid.org/0000-0002-0584-2966

c. (iD) http://orcid.org/0000-0001-6688-0600

d. (iD http://orcid.org/0000-0003-1088-2126

e. (iD http://orcid.org/0000-0001-9078-3296

Submitted: 25 September 2017. Accepted: 17 July 2018

Study carried out at the Universidade de Pernambuco - UPE - Recife (PE) Brasil.

\section{Obstructive sleep apnea and quality of life in elderly patients with a pacemaker}

Tatiana Albuquerque Gonçalves de Lima',a, Evandro Cabral de Brito ${ }^{2, b}$, Robson Martins ${ }^{2, c}$, Sandro Gonçalves de Lima ${ }^{3, d}$, Rodrigo Pinto Pedrosa ${ }^{2, e}$

\begin{abstract}
Objective: To evaluate quality of life in elderly patients with obstructive sleep apnea (OSA) who have a pacemaker. Methods: This was a cross-sectional study involving elderly patients ( $\geq 60$ years of age) with a pacemaker. The dependent variable was quality of life, as evaluated with the Medical Outcomes Study 36-item Short-Form Health Survey (SF-36). Sociodemographic and clinical parameters, including anxiety and depression (Hospital Anxiety and Depression Scale score), as well as the presence of OSA (defined as an apnea-hypopnea index $\geq 15$ events/h), were analyzed as independent variables. Patients with cognitive/neurological deficits or decompensated heart failure were excluded. Results: We evaluated 72 patients, 17 (23.6\%) of whom presented OSA. Of those 17 patients, $9(52.9 \%)$ were male. The mean age was $72.3 \pm 9.3$ years. A diagnosis of OSA was not associated with gender $(p=0.132)$, age $(p=0.294)$, or body mass index $(p=0.790)$. There were no differences between the patients with OSA and those without, in terms of the SF-36 domain scores. Fourteen patients (19.4\%) presented moderate or severe anxiety. Of those 14 patients, only $3(21.4 \%)$ had OSA $(p=0.89$ vs. no OSA). Twelve patients (16.6\%) had moderate or severe depression. Of those 12 patients, only $2(16.6 \%$ ) had OSA ( $p=0.73$ vs. no OSA). Conclusions: In elderly patients with a pacemaker, OSA was not found to be associated with quality of life or with symptoms of anxiety or depression.
\end{abstract}

Keywords: Quality of life; Aged; Sleep apnea, obstructive.

\section{INTRODUCTION}

Obstructive sleep apnea (OSA) is a respiratory disorder that is quite common, affecting up to one third of the adult population and reaching an even higher prevalence in the elderly. ${ }^{(1)}$ It has been associated with various adverse events, including cardiovascular disease, occupational problems, and motor vehicle accidents, resulting in decreased quality of life (QoL), as well as increased morbidity and mortality. ${ }^{(2-4)}$

It is understood that $\mathrm{QoL}$ is something intrinsic that can be evaluated only by the individual in question. Because expectations regarding health and the ability to deal with limitations can affect the self-perception of health and satisfaction with life, two individuals with the same health status may evaluate their QoL in very different manners. ${ }^{(5-7)}$

In recent decades, there has been a clear demographic change in Brazil, in terms of the aging of the population, which has followed the pattern observed in many other developing countries. It is estimated that, by 2020, the elderly population in Brazil will be the sixth largest in the world, comprising approximately 32 million people. ${ }^{(8,9)}$

The classic signs and symptoms of illness are not direct correlates of the psychic and social aspects of life in elderly individuals, because well-being in old age requires a balance among the various dimensions of QoL. The concept of QoL in old age is more closely related to autonomy and independence than to the presence or absence of disease. ${ }^{(6,10)}$ Therefore, self-assessment is not only quite practical but is also strongly associated with the actual health status in the elderly. $(6,10,11)$

OSA can affect important QoL domains, such as limitations in activities of daily living, emotional aspects, and interpersonal relationships, none of which are explored during a sleep study. Therefore, the objective of the present study was to evaluate QoL, as well as to determine whether OSA is associated with $\mathrm{QoL}$, in elderly individuals.

\section{METHODS}

This was a cross-sectional cohort study. The study population was composed of 72 elderly patients ( $\geq 60$ years of age), all of whom had a pacemaker, treated between December of 2013 and September of 2014 at the Outpatient Pacemaker Clinic of the Pronto-Socorro Cardiológico Universitário de Pernambuco (PROCAPE University of Pernambuco Emergency Cardiology Hospital), located in the city of Recife, Brazil. The dependent variable was QoL. The following were analyzed as independent variables: age, gender, level of education, level of physical activity, anxiety, depression, use of psychotropic medications, presence of OSA, excessive daytime sleepiness, body mass index, systemic arterial hypertension, acute myocardial infarction, and diabetes 
mellitus. Patients with cognitive or neurological deficits were excluded, as were those with decompensated heart failure. The research protocol was developed in accordance with Brazilian National Health Council Resolution no. 466/2012, which deals with the ethical aspects of research involving human beings in Brazil. After permission to carry out the study at the PROCAPE Outpatient Pacemaker Clinic had been obtained, the project was submitted to the Research Ethics Committee of the Hospital Oswaldo Cruz/PROCAPE, via the Plataforma Brasil (CAAE no. 07859513.4.0000.5207). All participating patients gave written informed consent.

\section{Instruments for assessment}

All data were collected by the same researcher. Demographic and clinical data were obtained from an interview with the patient, in which standardized data collection forms were used.

\section{Medical Outcomes Study 36-item Short-Form Health Survey}

The Medical Outcomes Study 36-item Short-Form Health Survey (SF-36) is a generic, self-report questionnaire consisting of 36 items grouped into eight domains ${ }^{(12)}$ : functional capacity, role-physical, bodily pain, general health, vitality, social functioning, role-emotional, and mental health. Higher SF-36 scores indicate better QoL.

\section{Hospital Anxiety and Depression Scale}

The Hospital Anxiety and Depression Scale (HADS) comprises fourteen items, divided into two subscales with seven items each(13): the anxiety subscale; and the depression subscale. Each item is scored from 0 to 3 , the maximum score therefore being 21 for each of the subscales. To avoid any influence of somatic disturbances on the scores, we excluded all questions regarding symptoms of anxiety or depression that were related to physical disorders (e.g., dizziness, headaches, insomnia, and fatigue). Questions regarding symptoms related to severe mental disorders were also excluded, given that the HADS has been shown to be a valid, reliable instrument for evaluating anxiety or depression in nonpsychiatric patients. ${ }^{(14)}$

\section{Sleep study}

All participants underwent overnight monitoring in the PROCAPE Sleep and Heart Laboratory, with a portable respiratory monitor (Embletta, PDS; Medcare, Reykjavik, Iceland). The monitoring involved continuous oximetry, the use of a thoracoabdominal belt for detecting respiratory work, monitoring of airflow through a nasal cannula, the use of position sensors, heart rate recording (through pulse oximetry), and snore detection. Apnea was defined as a $>90 \%$ reduction in airflow, whereas hypopnea was defined as a $30 \%$ reduction in airflow, accompanied by a $4 \%$ decrease in oxygen saturation. ${ }^{(14)}$ The final result was expressed in terms of the apnea-hypopnea index, calculated by dividing the total number of apnea and hypopnea events by the total sleep time, in hours. An apnea-hypopnea index $\geq 15$ events/h was considered diagnostic of OSA. In addition, daytime sleepiness was assessed subjectively with the Epworth Sleepiness Scale. ${ }^{(15)}$ A total score $>10$ was considered indicative of excessive daytime sleepiness. ${ }^{(16)}$

\section{Statistical analysis}

In the data analysis, categorical variables are expressed as absolute and relative frequencies. Continuous variables are expressed as means and standard deviations or as medians and interquartile ranges. Comparisons of proportions between two or more groups were performed with Pearson's chi-square test. For the comparison of means, we used the Student's t-test for independent samples, whereas we used the Mann-Whitney test for the comparison of medians. In all tests, the level of significance adopted was $p<0.05$. Statistical analyses were performed with the Stata software, version 12.1SE (StataCorp LP, College Station, TX, USA).

\section{RESULTS}

Of the 72 patients evaluated, $17(23.6 \%)$ had OSA. Of those 17 patients, 9 (52.9\%) were male. The mean age was 73.4 years among the patients with OSA and 70.8 years among those without. Other demographic and clinical characteristics of the patients with and without OSA are shown in Table 1.

For the sample as a whole, the mean score on the Physical Component Summary of the SF-36, which encompasses the physical domains (functional capacity, role-physical, bodily pain, and general health), was 56.6. Among those domains, the mean score was lowest $(49.0 \pm 25.6)$ for the role-physical domain and highest (60.8 \pm 28.3$)$ for the bodily pain domain. On the Mental Component Summary of the SF-36, which encompasses the vitality, social functioning, role-emotional, and mental health domains, the mean score was 69.2 , being lowest $(67.6 \pm 26.8)$ for the mental health domain and highest $(70.5 \pm 29.9)$ for the social functioning domain.

There were no significant differences between the patients with and without OSA when the SF-36 domains were assessed separately. However, for five domains (functional capacity, role-physical, vitality, role-emotional, and mental health), the patients with OSA had higher (i.e., better) scores. Among the patients with OSA, the mean score was lowest (50.0 \pm 29.3$)$ for the role-physical domain and highest (75.6 \pm 17.1$)$ for the vitality domain. Comparing the mean scores obtained for each domain of the SF-36 (Table 2), we found that the scores were highest for the domains within the Mental Component Summary (vitality, social functioning, role-emotional, and mental health).

On the anxiety subscale of the HADS, 40 patients $(55.6 \%)$ presented scores within the normal range; 18 $(25.0 \%)$ presented scores indicative of mild anxiety; and only $14(19.4 \%)$ presented scores indicative of 
Table 1. Demographic and clinical characteristics of patients with pacemakers, with and without obstructive sleep apnea. ${ }^{a}$

\begin{tabular}{|c|c|c|c|}
\hline \multirow[t]{2}{*}{ Characteristic } & \multicolumn{2}{|c|}{ Group } & \multirow[t]{2}{*}{ p* } \\
\hline & $\begin{array}{l}\text { Without OSA } \\
\quad(n=55)\end{array}$ & $\begin{array}{l}\text { With OSA } \\
(n=17)\end{array}$ & \\
\hline Male gender & $18(32.7)$ & $9(52.9)$ & 0.132 \\
\hline Age, years & $70.8 \pm 8.7$ & $73.4 \pm 9.3$ & 0.294 \\
\hline $\mathrm{BMI}, \mathrm{kg} / \mathrm{m}^{2}$ & $27.4 \pm 4.6$ & $27.7 \pm 5.0$ & 0.790 \\
\hline Underweight & $7(13.0)$ & $2(11.8)$ & 0.991 \\
\hline Normal weight & $19(35.2)$ & $6(35.3)$ & \\
\hline Overweight & $28(51.9)$ & 9 (52.9) & \\
\hline Level of education & & & 0.948 \\
\hline Illiterate & $14(25.5)$ & $5(29.4)$ & \\
\hline Literate & $27(49.1)$ & $8(47.2)$ & \\
\hline$\geq 9$ years of schooling & $14(25.5)$ & $4(23.5)$ & \\
\hline Physically active & $12(21.8)$ & $3(17.6)$ & 0.711 \\
\hline Anxiety & & & 0.888 \\
\hline None & $31(56.4)$ & 9 (52.9) & \\
\hline Mild & $13(23.6)$ & $5(29.4)$ & \\
\hline Moderate to severe & $11(20.0)$ & $3(17.6$ & \\
\hline Depression & & & 0.726 \\
\hline None & $41(74.5)$ & $13(76.5)$ & \\
\hline Mild & $4(7.3)$ & $2(11.8)$ & \\
\hline Moderate to severe & $10(18.2)$ & $2(11.8)$ & \\
\hline Use of psychoactive medications & $8(14.5)$ & $3(17.6)$ & 0.756 \\
\hline Excessive daytime sleepiness & & & 0.947 \\
\hline None & $17(30.9)$ & $5(29.4)$ & \\
\hline Moderate risk & $5(9.1)$ & $2(11.8)$ & \\
\hline High risk & $33(60.0)$ & $10(58.8)$ & \\
\hline AHI, events/h & $7.4[4.5-12.0]$ & $26.9[23.2-35.7]$ & $<0.001$ \\
\hline Minimum $\mathrm{SpO}_{2}, \%$ & $87[79-90]$ & $82[72-84]$ & 0.006 \\
\hline Oxygen desaturation index, events/h & $7.4[3.2-12.6]$ & $29.0[18.0-34.9]$ & 0.000 \\
\hline Time at $\mathrm{SpO}_{2}<90 \%, \mathrm{~h}$ & $0.5[0-2.1]$ & $2.8[1.4-9.9]$ & 0.002 \\
\hline \multicolumn{4}{|l|}{ Comorbidities } \\
\hline Acute myocardial infarction & $10(18.5)$ & $4(23.5)$ & 0.651 \\
\hline Systemic arterial hypertension & $42(77.8)$ & $13(76.5)$ & 0.910 \\
\hline Diabetes mellitus & $14(25.9)$ & $1(5.9)$ & 0.077 \\
\hline Dyslipidemia & $18(34.0)$ & $6(33.3)$ & 0.961 \\
\hline
\end{tabular}

OSA: obstructive sleep apnea; BMI: body mass index; and AHI: apnea-hypopnea index. ${ }^{a}$ Values expressed as $\mathrm{n}(\%)$, mean \pm SD, or median [interquartile range]. *Proportions compared by Pearson's chi-square test; means compared by Student's t-test; and medians compared by the Mann-Whitney test.

Table 2. Mean scores on the Medical Outcomes Study 36-item Short-Form Health Survey, by domain, among patients with pacemakers: comparison between patients with and without obstructive sleep apnea. ${ }^{a}$

\begin{tabular}{|c|c|c|c|}
\hline \multirow[t]{2}{*}{ Domain } & \multicolumn{2}{|c|}{ Group } & \multirow[t]{2}{*}{$p^{*}$} \\
\hline & $\begin{array}{l}\text { With OSA } \\
(n=55)\end{array}$ & $\begin{array}{l}\text { Without OSA } \\
\quad(n=17)\end{array}$ & \\
\hline Functional capacity & $57,3 \pm 25,9$ & $67,1 \pm 24,2$ & 0,171 \\
\hline Role-physical & $48,6 \pm 30,6$ & $50,0 \pm 29,3$ & 0,872 \\
\hline Bodily pain & $61,4 \pm 27,6$ & $59,2 \pm 31,4$ & 0,783 \\
\hline General health & $57,4 \pm 19,5$ & $56,4 \pm 20,7$ & 0,847 \\
\hline Vitality & $66,6 \pm 24,4$ & $75,6 \pm 17,1$ & 0,164 \\
\hline Social functioning & $71,1 \pm 29,8$ & $68,4 \pm 31,0$ & 0,743 \\
\hline Role-emotional & $69,1 \pm 30,0$ & $72,5 \pm 31,7$ & 0,683 \\
\hline Mental health & $66,6 \pm 27,5$ & $70,8 \pm 25,1$ & 0,576 \\
\hline
\end{tabular}

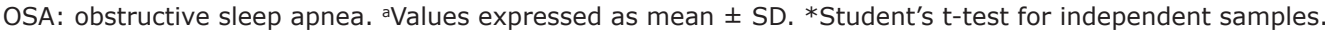


moderate or severe anxiety. Of those 14 patients, only $3(21.4 \%)$ had OSA. As can be seen in Figure 1, the score on the HADS anxiety subscale was not found to be associated with a diagnosis of OSA ( $p=0.89$ ).

On the depression subscale of the HADS, 54 patients (75.0\%) presented scores within the normal range; 6 $(8.3 \%)$ presented scores indicative of mild depression; and $12(16.6 \%)$ presented scores indicative of moderate or severe depression. Of those 12 patients, only 2 $(16.6 \%)$ had OSA. As can be seen in Figure 2, the score on the HADS depression subscale was not found to be associated with a diagnosis of OSA ( $p=0.73)$.

\section{DISCUSSION}

The present study evaluated QoL in elderly patients with and without OSA, producing some interesting data. The comparison of the means of the variables related to SF-36 domains between the patients with and without OSA did not reveal any associations between QoL and the presence of OSA. None of the SF-36 domains were found to be associated with OSA.

Because our study population consisted exclusively of elderly individuals, certain specific characteristics of that population could explain the results obtained. With advancing age, most physiological functions deteriorate, which contributes to sleep fragmentation in the elderly. Therefore, the prevalence of sleep-disordered breathing is expected to increase with age, as is that of OSA. ${ }^{(17)}$ However, in our study sample, the prevalence of OSA was relatively low $(\approx 24 \%$ ) in comparison with the $37-44 \%$ reported in other population-based studies with subgroups of the same age. $(1,18)$ That finding might be attributable to the lower mean body mass index in our sample $\left(\approx 27 \mathrm{~kg} / \mathrm{m}^{2}\right)$ and the use of portable monitoring with a more rigorous oxygen desaturation criterion ( $4 \%$ difference), without the use of electrocardiography. ${ }^{(18)}$ However, that does not imply that OSA necessarily has a negative impact on QoL. It should be born in mind that the instrument used for the evaluation of QoL, the SF-36, evaluates subject perceptions; that is, it involves a subjective evaluation that is influenced by several factors.

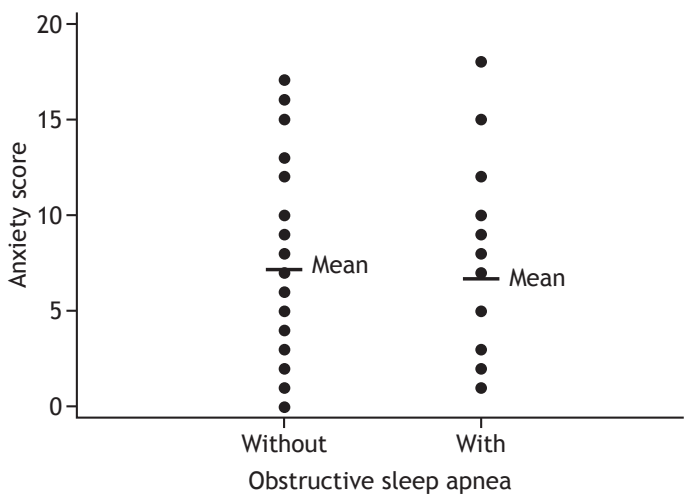

Figure 1. Distribution of scores on the anxiety subscale of the Hospital Anxiety and Depression Scale among patients with pacemakers, with and without obstructive sleep apnea.
Therefore, even when all of the limitations imposed by age are present, elderly individuals can perceive that scenario in a variety of ways. One of the factors associated with good health in the elderly is social engagement in activities of daily living, and this aspect is not contemplated in scales that assess QoL or in scales designed to quantify anxiety and depression.

In a study using the SF-36 to analyze the impact that the symptoms of OSA, especially excessive daytime sleepiness, have on QoL in individuals over 65 years of age ( $n=103)$, in comparison with younger subjects ( $n=$ 109), Martínez-García et al. ${ }^{(19)}$ also found no significant association between the presence of OSA and impaired QoL in the elderly. The authors emphasized the fact that, according to many studies, the elderly attribute excessive daytime sleepiness to their age, to the use of certain medications, or to a reduction in physical capacity, rather than to a pathological condition. ${ }^{(19)}$

It is known that the elderly are affected by some serious mental disorders, mainly those related to verbal activity, attention, memory, and logical reflection. (20) The cognitive deficit often observed in the elderly might also have contributed to a distorted assessment of QoL in the present study. A cognitive deficit could itself be associated with OSA. ${ }^{(21-23)}$

Another aspect that could explain the results obtained in the present study is the profile of the population studied. Our sample predominantly comprised individuals in a social situation characterized by many restrictions, their lower socioeconomic status obliging them to use public health care services. That population is not given sufficient attention or sufficient time to talk about their life and their overall health status during medical consultations. Many of our patients reported that during the application of the questionnaires they felt heard and accepted. That feeling could have contributed to the negative symptoms being underestimated, as a reflection of their QoL.

In a study involving a total of 63 subjects, Glebocka et al. ${ }^{(20)}$ evaluated the relationship between OSA, QoL, and psychological performance. The authors concluded that there were no significant differences between the subjects with and without OSA, in terms of the

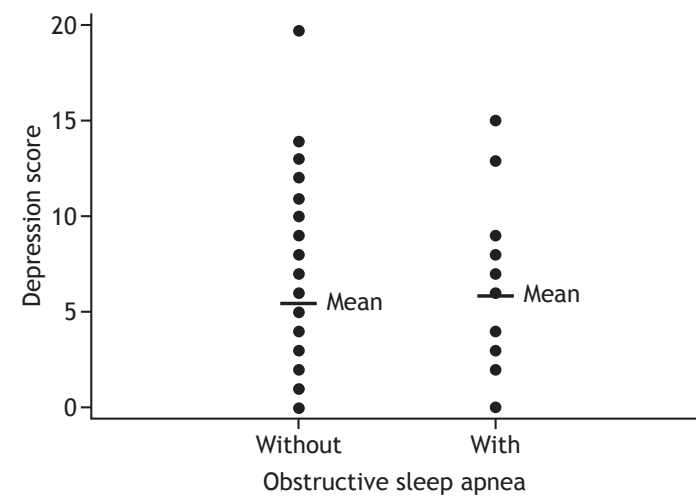

Figure 2. Distribution of scores on the depression subscale of the Hospital Anxiety and Depression Scale among patients with pacemakers, with and without obstructive sleep apnea. 
positive or negative emotions experienced. One possible explanation for the absence of psychiatric disorders in patients with OSA is that such patients might experience an improvement in their mood after admission to the hospital, in anticipation of being cared for by health care professionals and being given a diagnosis.

All of the domains studied by Dutt et al. ${ }^{(4)}$ and Lacasse et al. ${ }^{(24)}$ were affected by OSA, suggesting that QoL is impaired in patients with OSA, a finding corroborated by Iacono Isidoro et al., ${ }^{(25)}$ who pointed out that even mild OSA has a negative impact on QoL. However, in all of those studies, ${ }^{(4,24,25)}$ the individuals evaluated were $<60$ years of age. Other studies have also indicated that OSA results in impaired QoL, ${ }^{(26-30)}$ although few of those studies involved elderly patients. Even in the few studies that included elderly individuals, differences in relation to the mean age of the study population should be considered. For example, Baldwin et al.(31) found that sleep-disordered breathing had a negative impact on all SF-36 domains in a population of elderly individuals with a mean age of 63.2 years. That differs from the mean age of our study sample (72.1 years), which is comparable to that of the sample studied by Martínez-García et al., ${ }^{(19)}$ who pointed out that many authors have proposed the existence of two types of OSA, depending on the age of the affected individual. The type of OSA that occurs in younger individuals has a more evident symptomatology, whereas the type that occurs in older individuals has a more uncertain impact. The factors associated with sleep quality differ between younger and older individuals. Those differences reflect an age-related progression, which is universal, rather than a specifically cultural phenomenon. ${ }^{(30)}$

Another notable aspect is the potential influence that confounding factors, such as lifestyle, chronic diseases, and the regular use of psychotropic medications, have on the association between QoL and OSA. ${ }^{(19)}$ In the elderly, there are underdiagnosed diseases that alter QoL and affect sleep quality.

The sample of patients evaluated in the present study had some characteristics that could limit the external validity of our results: each of the elderly patients evaluated had a pacemaker, and a significant proportion were illiterate or had a very low level of education. Although the study design does not allow for conclusions about a cause-and-effect relationship, we highlight the inclusion of a comparison group of elderly individuals with pacemakers and OSA.

The results of the present study suggest that OSA is not associated with QoL in elderly patients with pacemakers.

\section{ACKNOWLEDGMENTS}

We are grateful to all of the patients, for making themselves available to participate in the study, as well as to the entire staff of the PROCAPE Casa de Chagas, for their assistance.

\section{REFERENCES}

1. Tufik S, Santos-Silva R, Taddei JA, Bittencourt LR. Obstructive sleep apnea syndrome in the Sao Paulo Epidemiologic Sleep Study. Sleep Med. 2010;11(5):441-6. https://doi.org/10.1016/j.sleep.2009.10.005

2. Karkoulias K, Lykouras D, Sampsonas F, Karaivazoglou K, Sargianou M, Drakatos $P$, et al. The impact of obstructive sleep apnea syndrome severity on physical performance and mental health. The use of SF-36 questionnaire in sleep apnea. Eur Rev Med Pharmacol Sci. 2013;17(4):531-6.

3. Gurubhagavatula I. Consequences of obstructive sleep apnoea Indian J Med Res. 2010;131:188-95

4. Dutt N, Janmeja AK, Mohapatra PR, Singh AK. Quality of life impairment in patients of obstructive sleep apnea and its relation with the severity of disease. Lung India. 2013;30(4):289-94. https:// doi.org/10.4103/0970-2113.120603

5. Testa MA, Simonson DC. Assessment of quality-of-life outcomes. $N$ Engl J Med. 1996;334(13):835-40. https://doi.org/10.1056/ NEJM199603283341306

6. Campolina AG, Dini PS, Ciconelli RZ. The impact of chronic disease on the quality of life of the elderly in São Paulo (SP, Brazil) [Article in Portuguese]. Cien Saude Colet. 2011;16(6):2919-25. https://doi. org/10.1590/S1413-81232011000600029

7. Segre M, Ferraz FC. The concept of health [Article in Portuguese] Rev Saude Publica. 1997;31(5):538-42. https://doi.org/10.1590/ S0034-89101997000600016

8. Veras R, Lima-Costa MF. Epidemiologia do Envelhecimento. In: Almeida Filho N, Barreto $\mathrm{ML}$, editors. Epidemiologia \& Saúde - Fundamentos, Métodos e Aplicações. São Paulo: Guanabara Koogan; 2012. p. 427-36.

9. Furtado LFV, Araújo PM, Soares FVS, Brito VM, Sousa LG, Melo ACL, et al. Epidemiologia do envelhecimento: dinamização, problemas e consequências. Kairós Gerontol. 2012;15(1): 55-69.

10. Pagotto V, Bachion MM, Silveira EA. Self-assessment of health by older Brazilians: systematic review of the literature [Article in Portuguese]. Rev Panam Salud Publica. 2013;33(4):302-10. https://

\section{doi.org/10.1590/S1020-49892013000400010}

11. Silva RJ, Smith-Menezes A, Tribess S, Rómo-Perez V, Virtuoso JS Jr. Prevalence and factors associated with negative health perception by the Brazilian elderly [Article in Portuguese]. Rev Bras Epidemiol. 2012;15(1):49-62. https://doi.org/10.1590/S1415790X2012000100005

12. Ciconelli RM, Ferraz MB, Santos W, Meinão I, Quaresma MR Tradução para a língua portuguesa e validação do questionário genérico de avaliação de qualidade de vida SF-36. Rev Bras Reumatol. 1999;39(3):143-50.

13. Bjelland I, Dahl AA, Haug T, Neckelmann D. The validity of the Hospital Anxiety and Depression Scale. An updated literature review. J Psychosom Res. 2002;52(2):69-77. https://doi.org/10.1016/S00223999(01)00296-3

14. Iber C, Ancoli-Israel S, Chesson A, Quan SF. The AASM Manual for the Scoring of Sleep and Associated Events: Rules, Terminology and Technical Specifications. Westchester, IL: American Academy of Sleep Medicine; 2007.

15. Bertolazi AN, Fagondes SC, Hoff LS, Pedro VD, Barreto SS, Johns MW. Portuguese-language version of the Epworth sleepiness scale: validation for use in Brazil. J Bras Pneumol. 2009;35(9):877-83. https://doi.org/10.1590/S1806-37132009000900009

16. Johns MW. A new method for measuring daytime sleepiness: the Epworth sleepiness scale. Sleep. 1991;14(6):540-5. https://doi. org/10.1093/sleep/14.6.540

17. Baldwin CM, Ervin AM, Mays MZ, Robbins J, Shafazand S, Walsleben J, et al. Sleep disturbances, quality of life, and ethnicity: The Sleep Heart Health Study. J Clin Sleep Med. 2010;6(2):176-83.

18. Heinzer R, Vat S, Marques-Vidal P, Marti-Soler H, Andries D, Tobback $\mathrm{N}$, et al. Prevalence of sleep-disordered breathing in the general population: the HypnoLaus study. Lancet Respir Med. 2015;3(4):3108. https://doi.org/10.1016/S2213-2600(15)00043-0

19. Martínez-García MA, Soler-Cataluña JJ, Román-Sánchez P, González V, Amorós C, Montserrat JM. Obstructive sleep apnea has little 
impact on quality of life in the elderly. Sleep Med. 2009;10(1):104-11. https://doi.org/10.1016/j.sleep.2007.11.009

20. Glebocka A, Kossowska A, Bednarek M. Obstructive sleep apnea and the quality of life. J Physiol Pharmacol. 2006;57 Suppl 4:111-7.

21. Kinugawa K, Nguyen-Michel VH, Mariani J. Obstructive sleep apnea syndrome: a cause of cognitive disorders in the elderly? [Article in French]. Rev Med Interne. 2014;35(10):664-9. https://doi. org/10.1016/j.revmed.2014.02.005

22. Gagnon K, Baril AA, Gagnon JF, Fortin M, Décary A, Lafond C, et al. Cognitive impairment in obstructive sleep apnea. Pathol Biol (Paris) 2014;62(5):233-40 https://doi.org/10.1016/j.patbio.2014.05.015

23. Vaessen TJ, Overeem S, Sitskoorn MM. Cognitive complaints in obstructive sleep apnea. Sleep Med Rev. 2015;19:51-8. https://doi. org/10.1016/..smrv.2014.03.008

24. Lacasse $Y$, Godbout $C$, Sériès F. Health-related quality of life in obstructive sleep apnoea. Eur Respir J. 2002;19(3):499-503. https:// doi.org/10.1183/09031936.02.00216902

25. Iacono Isidoro S, Salvaggio A, Lo Bue A, Romano S, Marrone O, Insalaco G. Quality of life in patients at first time visit for sleep disorders of breathing at a sleep centre. Health Qual Life Outcomes. 2013:11:207. https://doi.org/10.1186/1477-7525-11-207
26. Flemons WW, Tsai W. Quality of life consequences of sleepdisordered breathing. J Allergy Clin Immunol. 1997;99(2):S750-6. https://doi.org/10.1016/S0091-6749(97)70123-4

27. Shah N, Roux F, Mohsenin V. Improving Health-Related Quality of Life in Patients with Obstructive Sleep Apnea: What are the Available Options? Treat Respir Med. 2006;5(4):235-44. https://doi. org/10.2165/00151829-200605040-00002

28. Lopes C, Esteves AM, Bittencourt LR, Tufik S, Mello MT. Relationship between the quality of life and the severity of obstructive sleep apnea syndrome. Braz J Med Biol Res. 2008;41(10):908-13. https:// doi.org/10.1590/S0100-879X2008005000036

29. Ancoli-lsrael S. Sleep apnea in older adults-is it real and should age be the determining factor in the treatment decision matrix? Sleep Med Rev. 2007;11(2):83-5. https://doi.org/10.1016/j.smrv.2006.11.002

30. Lo CM, Lee PH. Prevalence and impacts of poor sleep on quality of life and associated factors of good sleepers in a sample of older Chinese adults. Health and Quality of Life Outcomes 2012;10:72. https://doi.org/10.1186/1477-7525-10-72

31. Baldwin CM, Grifith KA, Nieto JO, Connor GT, Walsleben JA, Readline S. The association of sleep-disordered breathing and sleep symptoms with quality of life in the Sleep Heart Health Study. Sleep 2001;24(1):96-105. https://doi.org/10.1093/sleep/24.1.96 